\title{
Immunomodulatory effects of Stachytarpheta cayennensis leaf extract and its synergistic effect with artesunate
}

Theophine C Okoye ${ }^{1 *}$, Peter A Akah ${ }^{1}$, Adaobi C Ezike ${ }^{1}$, Philip F Uzor ${ }^{2}$, Uchenna E Odoh ${ }^{3}$, Sebastian O lgboeme ${ }^{4}$, Uchechi B Onwuka ${ }^{1}$ and Sunday N Okafor ${ }^{1}$

\begin{abstract}
Background: The leaves of Stachytarpheta cayennensis C. Rich. (Verbenaceae) have been reported to possess potent anti-inflammatory and anti-malarial activities. Due to close association between inflammatory and immune responses, we evaluated the immunomodulatory activity of leaves extract of S. cayennensis. The combined effects of the leaves extract and artesunate, a standard antimalarial agent with immunomodulatory effects, were also evaluated.

Methods: The immunomodulatory activity of the methanol extract of the leaves of S. cayennensis (MESC) was evaluated in mice using the Delayed-Type hypersensitivity response (DTHR), primary and secondary humoral immune responses and the in vivo leucocyte mobilization tests. The immunomodulatory effect of artesunate and the combined effects of MESC and artesunate were evaluated using the phagocytic activity of polymorphonuclear neutrophils. Acute toxicity and lethality test in addition to the preliminary phytochemical studies of MESC were also performed.

Results: The MESC exhibited $64.21 \%$ inhibition of DTHR at $500 \mathrm{mg} / \mathrm{kg}$ dose and evoked $139.64 \%$ of phagocytic stimulation at $100 \mathrm{\mu g} / \mathrm{ml}$ dose. Also MESC significantly $(p<0.05)$ showed dose related stimulation of humoral immunity and a highest percentage leucocyte mobilization of $10.15 \%$ at $250 \mathrm{mg} / \mathrm{kg}$ dose. Artesunate offered a non-significant ( $p>0.05$ ) percentage phagocytic stimulation (PPS) while the combined effect of artesunate and MESC exhibited a significant $(p<0.05)$ dose dependent PPS with highest PPS of $393.77 \%$ at $100 \mu \mathrm{g} / \mathrm{ml}$. The $\mathrm{LD}_{50}$ of the MESC was estimated to be greater than $5000 \mathrm{mg} / \mathrm{kg}$ since there were no lethality and signs of acute intoxication after $48 \mathrm{~h}$ observation. Preliminary phytochemical analysis revealed the presence of carbohydrates, glycosides, flavonoids, saponins, alkaloids, terpenoids and steroids.

Conclusions: The results of this study indicated that MESC possesses immunostimulatory action with significant synergistic effects with artesunate, and can therefore, offer immune boosting activities in disorders of immune suppression.
\end{abstract}

Keywords: Cellular mediated immunity, Delayed type hypersensitivity, Immunomodulatory action, Stachytarpheta cayennensis, Artesunate

\footnotetext{
* Correspondence: theokuba@yahoo.com

${ }^{1}$ Department of Pharmacology \& Toxicology, Faculty of Pharmaceutical

Sciences, University of Nigeria, Nsukka, Enugu State 410001, Nigeria

Full list of author information is available at the end of the article
} 


\section{Background}

The scourge of acquired immune deficiency syndrome (AIDS) and other related immune deficiency diseases such as ebola virus disease and tuberculosis, especially in the developing countries, are established health concerns. In most cases, the suppression of immune system not only attracts opportunistic infections but also adversely affects the quality of life of patients. These, together with the attendant co-morbidity of immune disorders have recently stimulated research interest in the area of immune boosting potentials of medicinal plants.

The human immune system consists of two categories of defense mechanisms; the innate (non-specific) and the adaptive (specific) systems. These two mechanisms could be modified by substances, such as drugs and plant constituents, to either enhance or suppress their ability to resist invasion by pathogens $[1,2]$. The concern about the safety and adverse effects of the conventional immunomodulatory synthetic drugs has led to a growing interest in identifying and characterizing natural compounds with immunomodulatory effects possessing low profile toxicity $[3,4]$.

Medicinal plants have been reported to possess numerous secondary metabolites with potent immunomodulatory effects $[3,5,6]$. Most of these plants or plant parts are being used in folkloric medicine by rural dwellers to boost their immunity against infections. Studies have shown that many plants with proven anti-inflammatory effect also possess immunomodulatory effects based on the relationship between physiological mechanisms of inflammation and immune responses [7-9]. Some medicinal plants with established immunomodulatory effects are Panax ginseng, Viscum album, Tinospora cordifolia, Boerhaavia diffusa, Withania somnifera, Ocimum sanctum and Curculigo orchioides [10-15]. In addition, the immunomodulatory effects of artesunate, an artemisinin derivative isolated from the plant, Artemisia annua and related agents have also been documented [16,17].

The leaves of Stachytarpheta cayennensis C. Rich (Verbenaceae) have been documented to possess potent analgesic, antimalarial and antiinflammatory effects [18-20]. S. cayennensis, commonly known as "Gervâo" is a weedy annual (and sometimes perennial) herbaceous plant that grows mainly in the tropical rainforests, indigenous to most parts of tropical America, Mexico, Haiti, West Indies and South America [21]. The plant is used traditionally as anti-allergic, bronchodilatory, digestionstimulating, antacid and antidiarrhea [21], pain-relieving, antispasmodic and antiinflammatory [22,20], liver protective and detoxification [23], cellular protective, antioxidant and antimicrobial [22,24], anticonvulsant and sedative [25] agents.

The present study investigated the immunomodulatory potentials of methanol extract of S. cayennensis (MESC) leaves on cellular and humoral immune responses and assessed its synergistic effect with artesunate, a standard antimalarial agent with immunomodulatory potentials.

\section{Methods}

\section{Collection and preparation of plant material}

Fresh leaves of S. cayennensis were collected in the month of July, from Nsukka, Enugu State, Nigeria. The plant was identified and authenticated by Mr. Alfred Ozioko, a taxonomist of the International Center for Ethnomedicine and Drug Development (InterCEDD), Aku Road, Nsukka, Enugu State, Nigeria. The voucher specimen was deposited at the herbarium of the InterCEDD, Nsukka, Nigeria. The leaves were cleaned, cut into small pieces, dried and pulverized to coarse powder using a manual blender.

\section{Extraction of plant material}

The powdered dried leaves (700 g) were extracted with methanol using cold maceration for $48 \mathrm{~h}$. The entire bulk was filtered and concentrated using rotary evaporator under reduced pressure to obtain the methanol extract of the leaves of $S$. cayennensis (MESC; 13.6\% w/w) which was subjected to various tests. The MESC before administration was prepared by dissolving it in distilled water and diluting to appropriate concentration in the course of each experiment.

\section{Materials}

Pure artesunate sample (Emzor Pharma Nig. Ltd, Lagos) and methanol extract of the leaves of $S$. cayennensis (MESC).

\section{Animals}

Adult Swiss albino mice (22-30 g) and rat (200 g) of both sexes were obtained from the Animal House Facility of the Department of Pharmacology and Toxicology, University of Nigeria, Nsukka and used for this study. The animals were housed under standard conditions $\left(25 \pm 2^{\circ} \mathrm{C}\right)$ with free access to standard pellets (Guinea Feed Nigeria, Ltd.) and water. A healthy male sheep (for antigen used in Delayed Type Hypersensitivity Reaction test) was taken from the herd in the experimental animal facility of the Faculty of Veterinary Medicine, University of Nigeria, Nsukka. The sheep had free access to normal pasture in the farm. The animals (mice and rat) were transferred to the research area and were allowed a 14 day acclimatization period before the experiments. All animal experiments were conducted in compliance with the National Institute of Health Guide for Care and Use of Laboratory Animals (Pub No. 85-23, revised 1985) and in accordance with the University of Nigeria Ethics Committee on the use of laboratory animals, registered by the National Health Research Ethics Committee (NHREC) of Nigeria, with the number; NHREC/05/01/2008B. The 
protocols employed were submitted to and approved by the University Ethics Committee.

\section{Antigen}

Fresh sheep blood $(10 \mathrm{ml})$ was aseptically taken from the jugular vein of a healthy male sheep and transferred to heparinized tube. The blood samples were washed thrice in about $5-10 \mathrm{ml}$ of pyrogen-free sterile normal saline by centrifugation at $3000 \mathrm{rpm}$ for $10 \mathrm{~min}$ on each occasion. The washed SRBCs was adjusted to a concentration of $1 \times 10^{9}$ cells $/ \mathrm{ml}$ with sterile normal saline and used for immunization and challenge.

\section{Micro-organism}

Clinical isolates of Candida albicans obtained from the Microbiology Unit of the Department of Pharmaceutics and Pharmaceutical Microbiology, University of Nigeria, Nsukka. The C. albicans had been isolated from a high vaginal swab in the Medical Laboratory of a local hospital at Nsukka, Nigeria.

\section{Phytochemical analysis}

Qualitative phytochemical analysis was performed on MESC using standard procedures outlined by Harborne [26] and Trease and Evans [27]. Briefly, frothing test for saponins, Salkowski test for terpenoids, LiebermannBurchard tests for steroids, ferric chloride test for tannins, Keller-Killiani test for cardiac glycosides, Dragendorff's and Mayer's test for alkaloids, Fehling's test for reducing sugars, xanthoproteic test for proteins, iodine test for carbohydrates or starch and ammonia test for detection of flavonoids were performed for qualitative identification of the phytoconstituents present [28]. All reagents used for the phytochemical analysis were freshly prepared.

\section{Acute toxicity study}

The acute lethal dose $\left(\mathrm{LD}_{50}\right)$ of MESC was ascertained by the method described by Lorke [29]. Briefly, the study was performed in two phases. In the first phase, 9 mice were divided into 3 groups of 3 mice per group, and treated with the MESC at the doses of 10, 100 and $1000 \mathrm{mg} / \mathrm{kg}$ (p.o.) respectively. The animals were observed for $24 \mathrm{~h}$ for signs of toxicity. In the second phase, four mice were used. Three were treated separately with MESC doses of 1600, 2900 and $5000 \mathrm{mg} / \mathrm{kg}$ respectively, while the fourth (the control) received $10 \mathrm{ml} / \mathrm{kg}$ of distilled water. The animals were observed for $24 \mathrm{~h}$ period.

\section{Preparation of Candida albicans suspension}

Candida albicans culture was incubated in Sabouraud dextrose broth overnight and centrifuged to form a cell button at the bottom of the test tube. The supernatant was discarded and the cell button was washed 3-4 times with sterile phosphate buffer saline (PBS) and centrifuged.
The washed cell button was re-suspended in a mixture of PBS and rat serum in the proportion of 4:1. The count of C. albicans was adjusted to $1 \times 10^{8}$ cells/ml using the 0.5 McFarland standard.

\section{Preparation of the slide and evaluation of phagocytosis}

About $0.2 \mathrm{ml}$ of rat blood was smeared on sterile glass slide and incubated at $37^{\circ} \mathrm{C}$ for $20 \mathrm{~min}$ for clotting to occur. The slide was thereafter drained slowly with sterile normal saline in order not to wash off the adhered neutrophils or polymorphonuclear (PMN) leucoccytes. The slide consisting of neutrophils was flooded with the MESC, artesunate and combinations of the MESC and artesunate at different concentrations $(25,50$ and $100 \mu \mathrm{g} / \mathrm{ml})$, and were incubated at $37^{\circ} \mathrm{C}$ for $20 \mathrm{~min}$. The PMNs were covered with $C$. albicans suspension and incubated at $37^{\circ} \mathrm{C}$ for $1 \mathrm{~h}$. The slide was drained, fixed with methanol and stained with Giemsa stain and observed (100 X) under oil immersion and phagocytosis evaluated by the method described by Ganachari et al. [30]. The number of C. albicans cells phagocytosed by PMNs on the slide was determined microscopically for granulocytes using morphological criteria. This number was regarded as Phagocytic Index (PI) and was compared with the PI of the control treatment. Immunostimulation was calculated using the following equation:

Percentage Phagocytic Stimulation $($ PPS $)=$ PI (Test) - PI (Control) $/ \mathrm{PI}($ Control $) \times 100$.

\section{Determination of Delayed Type Hypersensitivity Response (DTHR)}

Twenty mice were randomly divided into four groups consisting of five animals per group. Delayed type hypersensitivity was induced in mice using Sheep Red Blood Cells (SRBCs). The MESC, suspended in distilled water, was administered by oral gavage to the animals. Groups 1 , 2 and 3 received 100, 250 and $500 \mathrm{mg} / \mathrm{kg}$ of the extract respectively while group 4 received levamisole (control). On day 0 , one hour after extract administration, the rats were sensitized by injecting $0.02 \mathrm{ml}$ of $10^{9}$ cells/ml of SRBCs subcutaneously, into the right hind foot paw. The animals were challenged on day 5 by subcutaneous injection of the same amount of antigen (SRBCs) into the left hind foot paw. The animals were treated with the extract 3 days prior to sensitization and continued till the challenge. The oedema produced by antigenic challenge in the left hind paw was measured as the difference in the paw thickness before and $24 \mathrm{~h}$ after the challenge. The paw thickness was measured with a pocket-sized screw gauge $[8,2,31]$.

\section{Determination of humoral immune response}

Twenty mice were randomly selected and divided into four groups of five animals in each group. The MESC, suspended in distilled water, was administered by oral 
gavage to the animals. Groups A, B and C received 100, 250 and $500 \mathrm{mg} / \mathrm{kg}$ body weight of MESC respectively, while group D (control) received distilled water. The method of Nelson and Mildenhall [32] was used to determine the effect of MESC on the antibody level of the animals resulting from sensitization with SRBCs. Briefly, on day zero, $0.1 \mathrm{ml}$ of the $10^{9} \mathrm{cell} / \mathrm{ml}$ SRBCs was given by intra-peritoneal injection (i.p.) to all the groups for immunization. The animals were challenged on day 5 by similar i.p. injection of the same amount of $10^{9} \mathrm{cell} / \mathrm{ml}$ SRBCs. The MESC was administered 3 days prior to sensitization and continued daily for 5 days after the challenge [2]. Primary antibody titre was determined on day 5 (before the challenge) and secondary titre on day 10. Blood samples were obtained by retroorbital puncture into test tubes and allowed to clot. A $25 \mu \mathrm{l}$ serum for each sample was obtained after centrifugation and serially diluted two-fold in 96-U well microtitre plates using pyrogen-free serial normal saline. The last well on each row contained sterile normal saline as control. The diluted sera were challenged with $25 \mu \mathrm{l}$ of $1 \% \mathrm{v} / \mathrm{v}$ SRBCs in the plates and then incubated at $37^{\circ} \mathrm{C}$ for $1 \mathrm{~h}$. The highest dilution giving rise to visible heamagglutination was taken as antibody titre. Antibody titres were expressed in graded manner, the minimum dilution (1/2) being ranked as 1 (calculated as $\log _{2}$ of the dilution factor).

\section{In vivo leucocyte mobilization test}

The method of Ribeiro et al. [33] was used in the test for the effect of MESC on the in vivo leucocyte mobilization induced by inflammatory stimulus. Mice were divided into four groups of five animals each. Groups I - III received MESC (100, 250 and $500 \mathrm{mg} / \mathrm{kg}$, respectively) while group IV received the vehicle. One hour after the administration of the extract, each mice in the groups received injection (i.p.) of $0.5 \mathrm{ml}$ of $3 \% \mathrm{w} / \mathrm{v}$ agar suspension in normal saline. Four hours later, the mice were sacrificed and the peritoneum washed with $5 \mathrm{ml}$ of a $5 \%$ solution of EDTA in Phosphate Buffered Saline (PBS). Total and differential leucocyte counts (TLC and DLC) were performed on the perfusates while the percentage leucocyte mobilization (PLM) was calculated using the formula; PLM (\%) = TLC (Test) - TLC $($ Control $) /$ TLC $($ Control $) \times 100$.

\section{Statistical analysis}

The results from the experiment were analyzed using one way Analysis of variance (ANOVA; Dunnett post hoc test) and expressed as the mean values for each group \pm SEM. The statistical significance between the test and the control groups were considered at $\mathrm{p}<0.05$.

\section{Results}

\section{Preliminary phytochemical analysis}

Results of preliminary phytochemical analysis of the MESC showed the presence of carbohydrates, glycosides, flavonoids, saponins, alkaloids, terpenoids and steroids (Table 1).

\section{Acute toxicity and lethality test}

The MESC exhibited an estimated $\mathrm{LD}_{50}$ greater than $5000 \mathrm{mg} / \mathrm{kg}$ (per oral) and did not cause any lethality and signs of acute intoxication after $48 \mathrm{~h}$ observation period. This was in line with other documented work on the leaves of S. cayennensis [24,23].

\section{Effect on phagocytic activity of polymorphonuclear leucocytes}

Artesunate at the doses tested exhibited non-significant ( $p>0.05$ ) phagocytic stimulation compared to the control (Figure 1). MESC also at doses tested exhibited no significant ( $\mathrm{p}>0.05)$ phagocytic stimulation except the $100 \mu \mathrm{g} / \mathrm{ml}$ dose which exhibited significant $(\mathrm{p}<0.05)$ phagocytic stimulation compared to the control. Moreover, the combined doses of the MESC and artesunate exhibited significant $(\mathrm{p}<0.05)$ phagocytic stimulation (Figure 1). At $100 \mu \mathrm{g} / \mathrm{ml}$ concentration, artesunate, MESC, levamisole and artesunate plus MESC showed percentage phagocytic stimulation of $17.75,139.64,223.66$ and $393.77 \%$ respectively (Figure 2). In addition the combined doses of the MESC and artesunate exhibited the highest phagocytic index (PI) and percentage phagocytic stimulation compared to the effects of the separate doses, the control and the levamisole, a standard agent (Figures 1 \& 2).

\section{Determination of Delayed Type Hypersensitivity Response (DTHR)}

The MESC at the doses tested showed significant $(\mathrm{p}<0.05)$ inhibition of delayed type hypersensitivity response. The

Table 1 Phytochemical constituents of the leaf extract of S. cayennensis

\begin{tabular}{lc}
\hline Constituent & MESC \\
\hline Carbohydrates & + \\
Reducing sugar & + \\
Glycosides & + \\
Flavonoids & + \\
Saponins & + \\
Alkaloids & + \\
Terpenoids & + \\
Tannins & - \\
Resins & - \\
Steroids & + \\
\hline
\end{tabular}

+ = present; - = absent. 


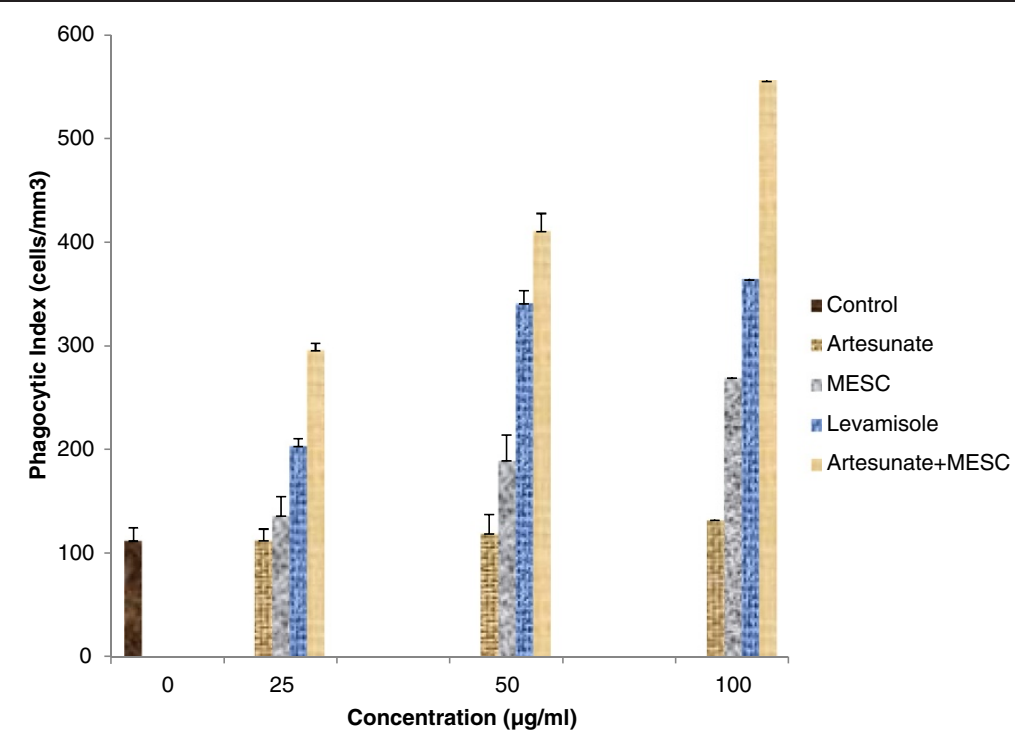

Figure 1 Phagocytic indexes (PI) of methanol extract of Stachytarpheta cayennensis (MESC), levamisole, artesunate and the combined effects of MESC and artesunate. PI showed the degree of phagocytic activities of polymorphonuclear leucocytes.

extract, at $500 \mathrm{mg} / \mathrm{kg}$ dose, exhibited highest percentage inhibition of the DTHR of $64.21 \%$ greater than that of levamisole which was $58.05 \%$ (Table 2).

\section{Determination of humoral immune response}

The MESC caused dose dependent statistically significant $(\mathrm{p}<0.05)$ elevation in the secondary antibody titres at the doses treated compared with the control. Moreover, MESC at all doses tested exhibited increased secondary mean titre values from the primary means titre values (Table 3 ).

\section{In vivo leucocytes mobilization test}

The result of the in vivo leucocyte mobilization showed that MESC produced a dose-dependent increase in the peritoneal percentage leucocyte mobilization up to the $250 \mathrm{mg} / \mathrm{kg}$ dose as well as that of the neutrophil differential analysis. However, MESC showed a non-dose-

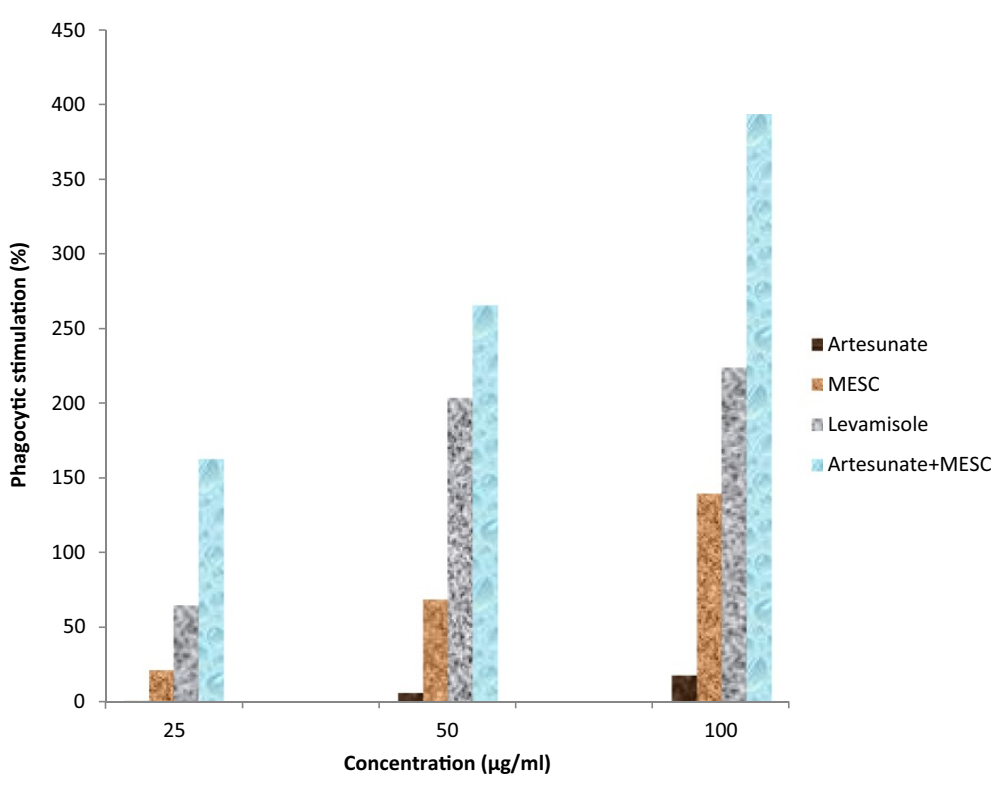

Figure 2 Percentage of phagocytic stimulation of the Stachytarpheta cayennensis extract (MESC), levamisole, artesunate and the combined effects of MESC and artesunate. 
Table 2 The effect MESC on delayed type hypersensitivity reaction

\begin{tabular}{lccc}
\hline Treatment & Dose $(\mathbf{m g} / \mathbf{k g})$ & Paw thickness $(\mathbf{m m})$ & Inhibition of DTHR (\%) \\
\hline MESC & 100 & $0.840 \pm 0.07^{*}$ & 55.79 \\
MESC & 250 & $0.770 \pm 0.03^{*}$ & 59.47 \\
MESC & 500 & $0.680 \pm 0.06^{*}$ & 64.21 \\
Levamisole & 2.5 & $0.797 \pm 0.22^{*}$ & 58.05 \\
Control & - & $1.900 \pm 0.07$ & - \\
\hline
\end{tabular}

Values are expressed as the mean \pm SEM using ANOVA, Dunnet as Post hoc. ${ }^{*} \mathrm{p}<0.05$ compared with the control; $\mathrm{n}=5$.

dependent mobilization of the lymphocyte differential analysis while the $250 \mathrm{mg} / \mathrm{kg}$ dose exhibited highest percentage leucocyte mobilization of $10.15 \%$ (Table 4).

\section{Discussion}

Findings from this study showed that MESC exhibited potent immunomodulatory effect on both humoral mediated and cell mediated immune responses. On humoral mediated immune response, MESC enhanced antibody synthesis whereas it stimulated phagocytic activity of polymorphonuclear leucocytes (PMNs) and suppressed the delayed type hypersensitivity reaction induced by SRBCs which are all cell-mediated events. It also enhanced leukocyte migration under inflammatory stimulus.

The increase in antibody titre evoked by MESC clearly indicates stimulation of the humoral immunity. Humoralmediated immunity involves the production specific antibodies (immunoglobulins) by bursa equivalent lymphocytes or plasma cells following sensitization to specific antigen [34]. Humoral immunity or antibody-mediated immunity is part of the body's adaptive immune response produced by the B-cell lymphocytes responsible for antibody production. It is activated by the alpha globulin antibodies on contact with antigenic substances such as proteins or polysaccharides foreign to the body. By stimulating antibody production, MESC may augment the body's immunity and enhance its capacity to contain infections of both bacterial and viral origins, which are organisms responsible for body's immune depletion.

In addition to augmenting the humoral immune response, MESC also increased phagocytic activity of neutrophils which suggests that it may enhance phagocytic activity of polymorphonuclear leukocytes and other phagocytic cells like macrophages. PMNs which can engulf, kill and digest microorganisms are usually the primary granulocytes attracted to invading pathogens by chemotaxins for destruction and elimination of the pathogens [35]. Phagocytic activity provides another line of defense against pathogenic invasion and contributes to strengthening the body's immunity.

Besides the phagocytic actions of these cells at sites of inflammation or microbial invasion, the extent of their migration is equally important. Fortunately, the effect of MESC on leukocyte migration also showed it may enhance cell migration under inflammatory stimulus. Our results showed that treatment with MESC increased total and differential cell counts at the sites of injection of the inflammogen. The import of this action is that MESC may likely quicken cellular response to inflammation and microbial invasion in addition to stimulating and enhancing their immunological mechanisms such as phagocytosis. These actions clearly indicate immuneboosting properties of MESC.

The immunomodulatory activity of MESC alone was comparable to that of levamisole, a standard immunomodulatory agent. Levamisole, an immunostimulant, has the tendency to restore depressed immune function of the B-lymphocytes, T-lymphocytes, monocytes and macrophages [35]. The combined treatment of artesunate, a derivative of artemisinin with immunomodulatory effects [17], and MESC exhibited enhanced immunomodulatory activity on phagocytic activity of PMNs. The enhanced

Table 3 The effect of MESC on primary and secondary humoral immune response

\begin{tabular}{llll}
\hline Treatment & Dose $\mathbf{( m g / k g )}$ & Primary (mean titre) & Secondary (mean titre) \\
\hline MESC & 100 & $2.83 \pm 0.17$ & $3.00 \pm 0.00$ \\
MESC & 250 & $3.38 \pm 0.43$ & $3.52 \pm 0.87^{*}$ \\
MESC & 500 & $3.75 \pm 0.25$ & $4.25 \pm 0.87^{*}$ \\
Control & - & $3.75 \pm 0.25$ & $2.30 \pm 0.45$ \\
\hline
\end{tabular}

Values are expressed as the mean \pm SEM using ANOVA, Dunnet as Post hoc. ${ }^{*} \mathrm{p}<0.05$ compared with the control; $\mathrm{n}=5$. 
Table 4 The effect of MESC on in-vivo Leucocytes mobilization

\begin{tabular}{llllll}
\hline Treatment & Dose $(\mathbf{m g} / \mathbf{k g})$ & TLC $\left(\right.$ cell $\left.\mathbf{~ m m}^{-\mathbf{3}}\right)$ & Leucocytes mobilization $(\%)$ & Differentials \\
\cline { 4 - 6 } & & & Neutrophil & Lymphocytes \\
\hline MESC & 100 & $46.50 \pm 4.99$ & -5.58 & $0.75 \pm 0.16$ & $44.80 \pm 4.69$ \\
MESC & 250 & $54.25 \pm 18.20$ & 10.15 & $4.49 \pm 1.84$ & $29.67 \pm 11.97$ \\
MESC & 500 & $50.25 \pm 6.57$ & 2.03 & $3.79 \pm 1.38$ & $46.54 \pm 5.56$ \\
Control & - & $49.25 \pm 6.10$ & - & $4.15 \pm 0.78$ & $45.11 \pm 6.67$ \\
\hline
\end{tabular}

Values are expressed as the mean \pm SEM using ANOVA, Dunnet as Post hoc, $\mathrm{n}=5$.

effect on phagocytic index elicited by the artesunateMESC combination could be due to increased phagocytosis by the PMNs (neutrophils) exhibited by both agents. The PMNs being the first of the blood leucocytes to enter an inflamed cellular area can exhibit appreciable modulation of pro-inflammatory cytokines such as TNF- $\alpha$, IL-1 and IL-10. Modulation of cytokines by artesunate could be a possible mechanism of its immunomodulatory actions since previous studies have reported the immunomodulatory effects of artesunate on cytokine production [36,17]. Although the scope of this study may not permit elucidation of the specific mechanisms associated with the actions of MESC on humoral and cell-mediated immunity, augmentation or modulation of the immune system is supposedly mediated through opsonization, direct neutralization of antigen, agglutination of antigen and activation of complement system to cause lyses and death of antigenic cells [37]. Additionally, the leaf extract of $S$. cayennensis has been reported to possess antimalarial activity [19], it therefore, implies that the combined effect of MESC and artesunate may not only stimulate immune system, but also offer a good synergistic effect in the eradication of malaria parasites, thus proffering a possible new usage. In sub-Saharan Africa where there is high prevalence of malarial scourge, this combination will be a good therapeutic advantage especially to rural dwellers.

Studies on DTHR showed that MESC suppressed DTHR in treated animals. DTHR is a feature of chronic inflammation. In chronic inflammatory conditions such as rheumatoid arthritis, there is usually the manifestation of delayed hypersensitivity in the cells [38]. DTHR is a T-cell mediated event and the extent to which MESC or its constituents interferes with such reactions is not clear to us. The inhibitory and suppressive actions of MESC on DTHR induced by SRBCs could arise from mechanisms associated with its anti-inflammatory effect and may contribute to the usefulness of this plant in disorders of chronic inflammation such as arthritis and other musculoskeletal pains $[18,20]$. Elsewhere, artesunate and other artemisinin derivatives have been shown to markedly suppress DTHR on chronic administration in laboratory animals [17].
The results of qualitative phytochemical analysis revealed the presence of carbohydrates, glycosides, flavonoids, saponins, alkaloids, terpenoids and steroids. Although no constituents could be linked to the immunomodulatory properties of the plant at this stage, studies have shown that different types of flavonoids may stimulate human peripheral blood leukocyte proliferation $[39,40]$. Flavonoids have reported to cause increase in the helper $\mathrm{T}$ cells, interleukin 2 (IL-2), interferon and macrophages; hence they are useful in several diseases of immune dysfunction [41-43].

Acute toxicity studies of MESC showed an estimated $\mathrm{LD}_{50}$ greater than $5000 \mathrm{mg} / \mathrm{kg}$, which is an indication of relative safety and remote risk of acute intoxication.

\section{Conclusion}

In conclusion, this study showed that the leaves of S. cayennensis exhibited potent immunomodulatory properties. Combination of the extract with artesunate showed synergistic immunomodulatory effect, and could offer additional benefit in malaria treatment.

\section{Competing interest}

The authors declare that they have no competing interests.

\section{Authors' contributions}

TCO and PAA designed the study. TCO, PAA, SOI, UBO and SNO performed the experiments while TCO, PAA, ACE, UEO and PFU prepared the manuscript for publication. All authors read and approved the final manuscript.

\section{Acknowledgement}

The authors wish to appreciate Mr. Alfred Ozioko, a taxonomist, with the International Center for Ethnomedicine and Drug Development (InterCEDD), Aku Road Nsukka, Enugu State, Nigeria for plant collection and identification.

\section{Author details}

${ }^{1}$ Department of Pharmacology \& Toxicology, Faculty of Pharmaceutical Sciences, University of Nigeria, Nsukka, Enugu State 410001, Nigeria. ${ }^{2}$ Department of Pharmaceutical \& Medicinal Chemistry, Faculty of

Pharmaceutical Sciences, University of Nigeria, Nsukka, Enugu State 410001, Nigeria. ${ }^{3}$ Department of Pharmacognosy \& Environmental Medicines, Faculty of Pharmaceutical Sciences, University of Nigeria, Nsukka, Enugu State 410001, Nigeria. ${ }^{4}$ Department of Clinical Pharmacy \& Pharmacy management, Faculty of Pharmaceutical Sciences, University of Nigeria, Nsukka, Enugu State 410001, Nigeria.

Received: 13 December 2013 Accepted: 19 September 2014 Published: 5 October 2014 


\section{References}

1. William JE: Review of antiviral and immunomodulatory properties of plants of the Peruvian rainforest. Alter Med Rev 2001, 6:567-579.

2. Nworu CS, Akah PA, Okoli CO, Esimone CO, Okoye FBC: The effects of methanolic seed extract of Garcinia kola on some specific and nonspecific immune responses in mice. Int J Pharmacol 2007, 3(4):347-351.

3. Sharma ML, Rao CS, Duda PL: Immunostimulatory activity of Picrorhiza kurroa leaf extract. J Ethnopharmacol 1994, 41:185-192.

4. Wang JZ, Mao XJ, Ito H, Shimura K: Immunomodulatory activity of polysaccharide from Acanthopanex obovatus roots. Planta Med 1991 57:335-336

5. Lee Gl, Young HJ, Rakmin J, Nakagawa H, Tsurefuji S, Chang IM, Kim Y. Inhibitory effect of oriental herbal medicines on IL-8 induction in lipopolysacharide-activated rat macrophages. Planta Med 1995, 61:26-36

6. Sharma ML, Singh B, Chandan BK, Khajuria A, Kaul A, Bani S, Banerjeee SK, Gambhir SS: Actions of some flavonoids on specific and non-specific immune mechanisms. Phytomedicine 1996, 3(2):191-195.

7. SaiRam M, Sharma SK, llavazhagan G, Kurmar D, Selvamurthy W: Immunomodulatory effects of NIM-76, a volatile fraction from Neem oil. J Ethnopharmacol 1996, 55:133-139.

8. Shinde UA, Phadke AS, Nair AM, Mungantiwar AA, Dikshit VJ, Saraf MN Preliminary studies on the immunomodulatory activity of Cedrus deodara wood oil. Fitoterapia 1999, 70:333-339.

9. Okoli CO, Akah PA, Ezike AC: Effects of Culcasia scandens leaf extracts on chronic inflammation and specific cell-mediated immune response. J Trop Med Plants 2009, 10(2):163-166.

10. Mathew S, Kuttan G: Immunomodulatory and antitumor activities of Tinospora cardifolia. Fitoterapia 1999, 70:35-43.

11. Davis L, Kuttan G: Immunomodulatory activity of Withania Somnifera. J Ethnopharmacol 2000, 71:193-202.

12. Mediratta PK, Sharma KK, Singh S: Evaluation of immunomodulatory potential of Ocimum sanctum seed oil and its possible mechanism of action. J Ethnopharmacol 2002, 80:15.

13. Saraf MN, Damre AS, Gokhale AB, Phadke AS, Kulkarni KR: Studies of the immunomodulatory activity of flavonoidal fraction of Tephrosia purpurea. Fitoterapia 2003, 74:257-226.

14. Kuttan G, Sunila ES: Immunomodulatory and antitumor activity of Piper longum Linn. and piperine. J Ethnopharmacol 2004, 90:339-346.

15. Mishra SH, Bafna AR: Immunostimulatory effects of methanol extract of Curculigo Orchioides on immunosuppressed mice. J Ethnopharmacol 2006, 104:1-4.

16. Li WD, Dong YJ, Tu YY, Lin ZB: Dihydroartemisinin ameliorates lupus symptom of BXSB mice by inhibiting production of TNF- $a$ and blocking the signaling pathway NFKB translocation. Int Immunopharmacol 2006, 6:1243-1250.

17. Gumede B, Waako PJ, Folb PI, Ryffel B: Modulation of IFN- $\gamma$ TNF-a, IL-10 and IL-12 production by Artesunate in mitogen treated splenocytes. Int J Trop Med 2009, 4(2):65-69.

18. Schapoval EES, de Vargas MR, Chaves CG, Bridi R, Zuanazzi JA, Henriques AT: Antiinflammatory and antinociceptive activities of extracts and isolated compounds from Stachytarpheta cayennensis. J Ethnopharmacol 1998, 60(1):53-59.

19. Okokon JE, Ettebong E, Antia BS: In vivo antimalarial activity of ethanolic leaf extract of Stachytarpheta cayennensis. Indian J Pharmacol 2008, 40(3):111-113. doi:10.4103/0253-7613.42303.

20. Penido C: Anti-inflammatory and anti-ulcerogenic properties of Staphytarpheta cayennensis (L.C. Rich) Vahl. J Ethnopharmacol 2006, 104(1):225-233.

21. Mesia-vela S: Pharmacological study of Starphytarpheta cayennensis Val in rodents. Phytomedicine 2004, 11(7):616-624.

22. Lee $\mathrm{JH}$ : The effect of aceteoside on histamine release and arachidonic acid release in RBL-2H3 mast cells. Arch Pharm Res 2004, 29(6):508-513.

23. Park JC: Effects of methanol extract of Cirsium japonicum var ussuriense and its principle, hispidulin-7-0-neohesperidoside on hepatic alcoholmetabolizing enzymes and lipid peroxidation in ethanol-treated rats. Phytother Res 2004, 4:19-24.

24. Okoye TC, Akah PA, Okoli CO, Ezike AC, Mbaoji FN: Antimicrobial and antispasmodic activity of leaf extract and fractions of Stachytarpheta cayennensis. Asian Pacific J Trop Med 2010, 3(3):189-192.
25. Okoye TC, Aguwa CN, Okoli CO, Akah PA, Nworu CS: Evaluation of the anticonvulsant and sedative effects of leaf extracts of Stachytarpheta cayennensis. J Trop Med Plants 2008, 9(1):17-22.

26. Harborne JB: Phytochemical Methods: a guide to modern techniques of plant analysis. 2nd edition. London: Chapman and Hall; 1988:55-56.

27. Trease GE, Evans WC: "Test book of Pharmacognosy". 11th edition. London: Brailliare Tindall and Macmillian Publishers; 1989:176-180.

28. Sofowora SA: Medicinal Plants and Traditional Medicine in Africa, 3rd edition. Spectrum Books Publishers: Ibadan, Nigeria; 2008.

29. Lorke D: A new approach to practical acute toxicity testing. Arch Toxicol 1983, 54:272-289.

30. Ganachari MS, Kumar S, Bhat KG: Effects of Ziziphus jujuba leaves extract on phagocytosis by human neutrophils. J Nat Remedies 2004, 4:47-51.

31. Naved T, Siddiqui Jl, Ansari SH, Ansari AA, Mukhtar HM: Immunomodulatory activity of Mangifera indica L. fruits (cv. Neelam) J Nat Remedies 2005, 5:137-140.

32. Nelson DA, Mildenhall P: Studies on cytophilic antibodies. The production by mice of macrophage cytophilic antibodies to sheep erythrocytes: Relationship to the production of other antibodies and development of delayed type hypersensitivity. Aust J Exp Bio Med Sci 1967, 45:113-120.

33. Ribeiro RA, Flores CA, Cunha FQ, Ferreira SH: IL-8 causes in vivo neutrophil migration by a cell dependent mechanism. Immunology 1991, 73:472-477.

34. Dean JH, Murray MJ: Toxic responses of the immune system. In Casarett and Doull's Toxicology. 4th edition. Edited by Amdur MO, Doull J, Klaassen CD. New York: McGraw-Hill; 1993:282-286.

35. Rang HP, Dale MM, Ritter JM, Flower RJ: Local hormones, inflammation and immune reactions. In Rang and Dale's Pharmacology. 6th edition. Churchill Livingstone, Philadelphia: Elsevier; 2007:202-208.

36. Veerasubramania P, Gosi P, Limsomwong C, Walsh DS: Artesunate and a major metabolite, Dihydroartemisinin, diminish mitogen-induced lymphocyte proliferation and activation. Southeast Asian J Trop Med Public Health 2006, 37(5):838-847

37. Green RJ, Harris ND: Cell-mediated Immunity. In Pathology and Therapeutics for Pharmacists. London: Chapman and Hall; 1996:21-22.

38. Gallin J: Inflammation. In Fundamental Immunology. Edited by Paul WE. New York: Raven Press Ltd; 1993:1015-1032.

39. Ziauddin M, Phansalker N, Patki P, Diwanay S, Patwardhan B: Studies on the immunomodulatory effects of Ashwagandha. J Ethnopharmacol 1996, 50:69-76.

40. Middleton $\mathrm{E} \mathrm{Jr}$ : Effect of plant flavonoids on immune and inflammatory cell function. Adv Exp Med Biol 1998, 439:175-182.

41. Patwardin B, Kalbag D, Patki PS, Nagsampagi BA: Search for immunomodulatory agents: A review. Indian Drugs 1990, 28:56-63.

42. Chiang LC, Lean TN, Chiang W, Chang MC, Lin CC: Immunomodulatory activities of flavonoids, monoterpenoids, triterpenoids, iridoid glycosides and phenolic compounds of Plantago species. Planta Med 2003, 69:600-604.

43. Kawakita SW, Giedlin HS, Nomoto K: Immunomodulators from higher plants. J Nat Med 2005, 46:34-38.

doi:10.1186/1472-6882-14-376

Cite this article as: Okoye et al:: Immunomodulatory effects of Stachytarpheta cayennensis leaf extract and its synergistic effect with artesunate. BMC Complementary and Alternative Medicine 2014 14:376.

\section{Submit your next manuscript to BioMed Central and take full advantage of:}

- Convenient online submission

- Thorough peer review

- No space constraints or color figure charges

- Immediate publication on acceptance

- Inclusion in PubMed, CAS, Scopus and Google Scholar

- Research which is freely available for redistribution 